Petr Hruby - Tomas Nahlik - Dana Smetanova

\title{
EFFECTS OF BOUNDARY CONDITIONS ON THE MODAL AND SPECTRAL PROPERTIES OF THE SHAFT
}

Influence of boundary conditions (i.e. mounting type of shafts ends) on spectral and modal properties is studied in this paper. Cases with joints at both ends and with joint at one end and fixed end are described in detail. The vibration problem of rotating shaft is generalized to problem of vibration of the shaft in the rotating plane. The problem is illustrated on testing models. The real mounting type of shafts is presented.

Keywords: shaft, boundary conditions, critical velocity, deflection, vibration

\section{Introduction}

The calculation of modal and spectral properties of the shaft is among the basic calculations that are required to support propulsion projects for various vehicles, ships and construction machines.

The mathematical model of the rotating shaft is influenced by many factors, such as vibration noise [1], flexibility of shaft [2], increasing rotation velocity [3], workspace of universal joints [4] and others [5]. A number of powerful software packages for calculation of torsional vibration already exists [6].

This paper is devoted to study deflection, critical velocity and eigenvalues of frequencies in the rotating shaft. Influence of boundary conditions in mathematical model is illustrated on testing examples.

\section{Theoretical background}

The mathematical model of the rotating shaft is described by the $4^{\text {th }}$ order differential equation. An unknown function in the given differential equation is the shaft deflection depending on the distance from the shaft end.

By solving the equation, a general solution that includes all the solutions to the problem is calculated. The number of solutions is infinite.

The particular solution is obtained by applying the boundary conditions (i.e. mounting types of ends of the shaft - Figures 5 and 6, [7]).

This means that boundary conditions play significant role in the calculation of model (Table 2 and Table 4).

\subsection{Shaft with continuously distributed mass}

Consider a prismatic shaft, which rotates at constant angular velocity $\omega$. The shaft bends at critical velocity and it rotates in a bent state (see Figure 1). Centrifugal force $\mathrm{d} C$ acts on the shaft element $\mathrm{d} x$ (see Figure 1)

$\mathrm{d} C=\mu y(x) \omega^{2} \mathrm{~d} x$

where $y(x)$ is deflection depending on distance from shaft end $(0 \leq x \leq l), \mu$ is a specific mass per unit length of the shaft; $\mu=S \rho$ and $S$ is the cross-section of the shaft, $\rho$ is a density of the shaft material.

Continuous strain $q(x)$ of the length element is

$q(x)=\frac{\mathrm{d} C}{\mathrm{~d} x}=\mu y(x) \omega^{2}$.

as is well known that deflection curve satisfies

$E J y^{\prime \prime}(x)=-M_{0}(x)$

By differentiating the above equations twice, with $E J=$ constant , one obtains

$E J y^{I V}(x)=-M_{0}{ }^{\prime \prime}(x)=q(x)=\mu y(x) \omega^{2}$,

i.e.

$E J y^{I V}(x)-{ }_{0} \mu y(x) \omega^{2}=0$.

The above equation is rewritten to form

$y^{I V}(x)-a^{4} y(x)=0, a^{4}=\frac{\mu \omega^{2}}{E J}$.

Meanings of symbols in equations above are precisely described in Table 3.

\footnotetext{
Petr Hruby ${ }^{1}$, Tomas Nahlik ${ }^{2}$, Dana Smetanova ${ }^{2, *}$

${ }^{1}$ Department of Mechanical Engineering, Institute of Technology and Business, Ceske Budejovice, Czech Republic

${ }^{2}$ Department of Informatics and Natural Sciences, Institute of Technology and Business, Ceske Budejovice, Czech Republic

*E-mail of corresponding author: smetanova@vstecb.cz
} 


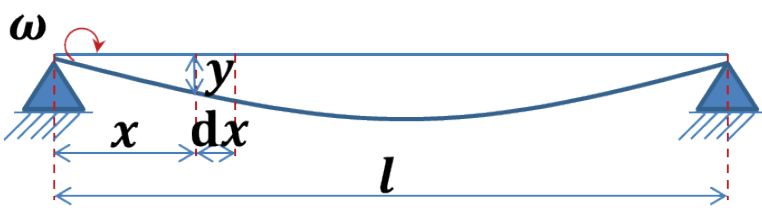

Figure 1 Shaft with joint ends

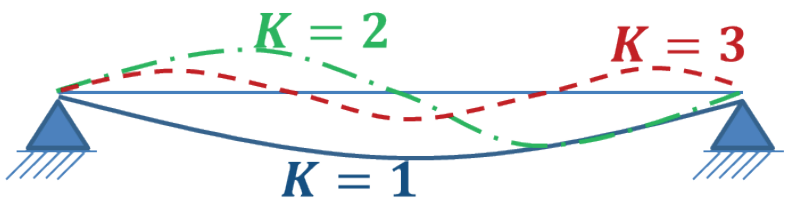

Figure 2 Deflections of a shaft

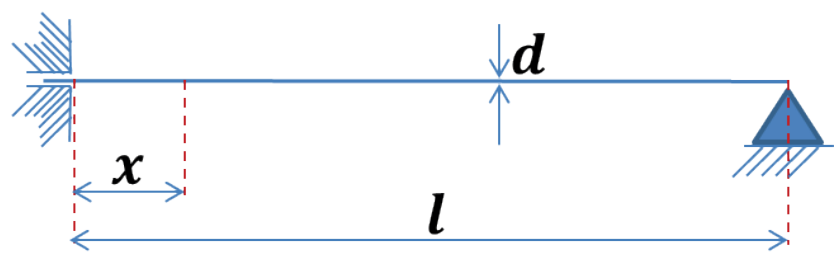

Figure 3 Shaft with joint and fixed end

Table 1 Boundary conditions at the ends of a shaft

\begin{tabular}{cccc}
\hline & & Mounting type \\
\cline { 2 - 4 } & Joint & Fixed end & Free end \\
Boundary conditions in $x=0$ or $x=l$ & $y(x)=0$, & $y(x)=0$, & $y^{\prime \prime}(x)=0$, \\
$y^{\prime \prime \prime}(x)=0$ & $y^{\prime \prime}(x)=0$ & 0 & $y^{\prime}(x)=0$ \\
\hline
\end{tabular}

The general solution of Equation (5), respectively Equation (6), is

$y(x)=A \cosh a x+B \sinh a x+C \cos a x+D \sin a x$.

The integration constants can be determined from the boundary conditions that correspond to the shaft's ends' mounting type. The particular solution is obtained by the straightforward calculation of the constants.

\subsection{Critical angular velocities of shaft with joints}

The shaft shown in Figure 1 (c.f. Table 1, mounting type A in Table 2) satisfies the boundary conditions

$y(0)=0, y(l)=0, y^{\prime \prime}(0)=0, y^{\prime \prime}(l)=0$.

Those boundary conditions (by straightforward calculation of Equation (7)) are equivalent to equations for integration constants

$A=0, C=0, B \sinh a l=0, D \sin a l=0$.

Note that $\sinh a l \neq 0$ for $\omega \neq 0$, than $B=0$. The last equation is satisfied if $D=0$ or are valid.sin $a l=0$ Equality $D=0$ means that there is no deflection of shaft and $D$ plays the role of the maximal deflection (amplitude). The solution of equation $\sin a l=0 \quad$ is $a l=K \pi$, where $K=1,2, \ldots, \quad\left(\right.$ i.e. $\left.a=\frac{K \pi}{l}, a^{4}=\left(\frac{K \pi}{l}\right)^{4}\right)$ and $\left(\frac{K \pi}{t}\right)^{4}=\frac{\mu}{E J} \omega^{2}$.
The infinite number of critical angular velocities was obtained. The $K$-th critical velocity is expressed by equation

$$
\begin{aligned}
\omega_{c r K} & =\left(K \frac{\pi}{l}\right)^{2} \sqrt{\frac{E J}{\mu}}=K^{2} \omega_{c r 1}, \\
\omega_{c r 1} & =\left(\frac{\pi}{r}\right)^{2} \sqrt{\frac{E J}{\mu}},
\end{aligned}
$$

where $\omega_{c r 1}$ is the first critical velocity $(K=1)$.

A shape of deflection curve depends on critical velocity. Expression for the deflection curve $y_{K}$ (see Figure 2) for the $K$-th critical velocity $\omega_{c r K}$ is

$$
y_{K}=D \sin \frac{K \pi x}{l}
$$

\subsection{Critical angular velocities of shafts with one fixed end}

The critical velocity of the shaft with fixed end is now determined by analytical method (see Figure 3 and Table 1, mounting type $\mathrm{E}$ in Table 2)

The parameter $d$ in Figure 3 indicates the shaft diameter (i.e. the characteristics of the cross-section).

Analytical solution (without damping and shifting forces and friction) is solution of differential Equation (5) (resp. Equation (6)). The general solution is of the form

$y(x)=A \cosh a x+B \sinh a x+C \cos a x+D \sin a x,(12)$

where $a=\sqrt[4]{\frac{\mu \omega^{2}}{E J}}$, with boundary conditions

$y(0)=0, y(l)=0, y^{\prime}(0)=0, y^{\prime \prime}(l)=0$. 
Table 2 Role of mounting types (i.e. boundary conditions) in solutions of the frequency equation

\begin{tabular}{|c|c|c|c|}
\hline & Mounting type & Frequency equation & Solutions \\
\hline A & & $\sin a l=0$ & $(a)_{k}=\frac{K \pi}{l}$ \\
\hline B & & $\cos a l \cosh a l=1$ & $\begin{aligned}(a)_{1} l & =0, \\
(a)_{2} l & =4.730, \\
(a)_{3} l & =7.853, \\
(a)_{4} l & =10.996,\end{aligned}$ \\
\hline $\mathrm{C}$ & & $\cos a l \cos a l=1$ & $\begin{aligned} \cdots \\
(a)_{1} l=4.730, \\
(a)_{2} l=7.853, \\
(a)_{3} l=10.996, \\
(a)_{4} l=14.134,\end{aligned}$ \\
\hline $\mathrm{D}$ & & $\cos a l \cosh a l=-1$ & $\begin{aligned} \cdots \\
(a)_{1} l=1.875, \\
(a)_{2} l=4.694, \\
(a)_{3} l=7.855, \\
(a)_{4} l=10.996,\end{aligned}$ \\
\hline $\mathrm{E}$ & & $\tan a l=\tanh a l$ & $\begin{aligned} \cdots \\
(a)_{1} l=3.927, \\
(a)_{2} l=7.069, \\
(a)_{3} l=10.210, \\
(a)_{4} l=13.352,\end{aligned}$ \\
\hline & & & \\
\hline
\end{tabular}

By straightforward calculation of the above conditions one obtain transcendental equation

$\tan a l=\tanh a l$

with solutions

$(a l)_{K}=\frac{4 K+1}{4} \pi, K=1,2, \ldots$

Therefore the $K$-th critical velocity is expressed by equation

$\omega_{c r K}=\left(\frac{4 K+1}{4} \frac{\pi}{l}\right)^{2} \sqrt{\frac{E J}{\mu}}$

and the first critical velocity is

$\omega_{c r 1}=\left(\frac{5}{4} \frac{\pi}{l}\right)^{2} \sqrt{\frac{E J}{\mu}} \doteq 15,4 \frac{1}{l^{2}} \sqrt{\frac{E J}{\mu}}$.

In Table 2 one can see role of the mounting type of shafts and beams in the frequency equation (c.f. [8]). The most obvious mounting types $\mathrm{A}$ and $\mathrm{E}$ of shafts are more precisely discussed above.

Technical realization of the most common mounting types $\mathrm{A}$ and $\mathrm{E}$ is presented in the Conclusion (see technical design in Figures 5 and 6).

See [8] and [9] for more details on theoretical background in mechanical properties and [10-12] for more details of the computational methods.

\section{Analytical solution of generalized problem}

The problem mentioned above is the vibration of a shaft in a plane. Generalization of the above problem is vibration of one-dimensional continuum in the rotating plane with angular velocity $\omega$. By analytical method it is possible to obtain the following description of the problem, c.f. [13].

$\frac{\partial^{4} y}{\partial x^{4}}-\frac{\rho S r^{2}}{4 E J} \cdot \frac{\partial^{4} y}{\partial t^{2} \partial x^{2}}+\frac{\rho S}{E J} \cdot \frac{\partial^{2} y}{\partial t^{2}}-$

$-\frac{\rho S r^{2} \omega^{2}}{4 E J} \cdot \frac{\partial^{2} y}{\partial x^{2}}-\frac{\rho S \omega}{E J} \cdot y=0$

Contrary to ordinary differential Equation (6), the above Equation (17) is partial differential equation.

Assume that each shaft cross-section performs an oscillating motion with the amplitude depending on location, with a time course identical along the entire shaft, i.e.

$y(x, t)=Y(x) e^{i \Omega t}$,

where $Y(x)$ is amplitude of deflection depending on coordinate $x$ and $\Omega\left[\mathrm{rad} \cdot \mathrm{s}^{-1}\right]$ is the natural frequency of relative oscillations.

Substituting Equation (18) to Equation (17), with undamping condition identical all the time, one obtains ordinary differential equation for amplitude as 
Table 3 Parameters of testing examples

\begin{tabular}{|c|c|c|c|}
\hline \multirow{2}{*}{ Parameter } & \multicolumn{2}{|c|}{ Value } & \multirow{2}{*}{ Description } \\
\hline & Simple shaft & Skoda 781 & \\
\hline$E$ & $2 \cdot 10^{11}$ & $2 \cdot 10^{11}$ & Modulus of elasticity $[\mathrm{Pa}]$ \\
\hline$\rho$ & 7800 & 7800 & Density $\left[k g \cdot m^{-3}\right]$ \\
\hline$l$ & 1 & 0.65 & Length $[m]$ \\
\hline$r$ & 0.0564 & 0.0105 & Radius $[m]$ \\
\hline$S$ & 0.01 & 0.0003 & Cross-section $\left[m^{2}\right]$ \\
\hline$J$ & $7.9578 \cdot 10^{-1}$ & $9.5466 \cdot 10^{-9}$ & $J=\frac{\pi}{4} \cdot r^{4}\left[m^{4}\right]$ \\
\hline$\mu$ & 78 & 2.7016 & $\mu=S \cdot \rho\left[k g \cdot m^{-1}\right]$ \\
\hline
\end{tabular}

Table 4 Critical velocities of testing examples based on different mounting types

\begin{tabular}{|c|c|c|c|c|c|}
\hline & & \multicolumn{4}{|c|}{$\omega_{K}\left[\mathrm{rad} \cdot \mathrm{s}^{-1}\right]$} \\
\hline & & 1 & 2 & 3 & 4 \\
\hline \multirow{2}{*}{ Simple Shaft } & 2 joints & 1409.82 & 5639.26 & 12688.35 & 22557.06 \\
\hline & 1 joint 1 fixed & 2202.84 & 7137.19 & 14891.18 & 25464.81 \\
\hline \multirow{2}{*}{ Skoda 781} & 2 joints & 621.01 & 2484.05 & 5589.11 & 9936.19 \\
\hline & 1 joint 1 fixed & 970.33 & 3143.87 & 6559.44 & 11217.03 \\
\hline
\end{tabular}

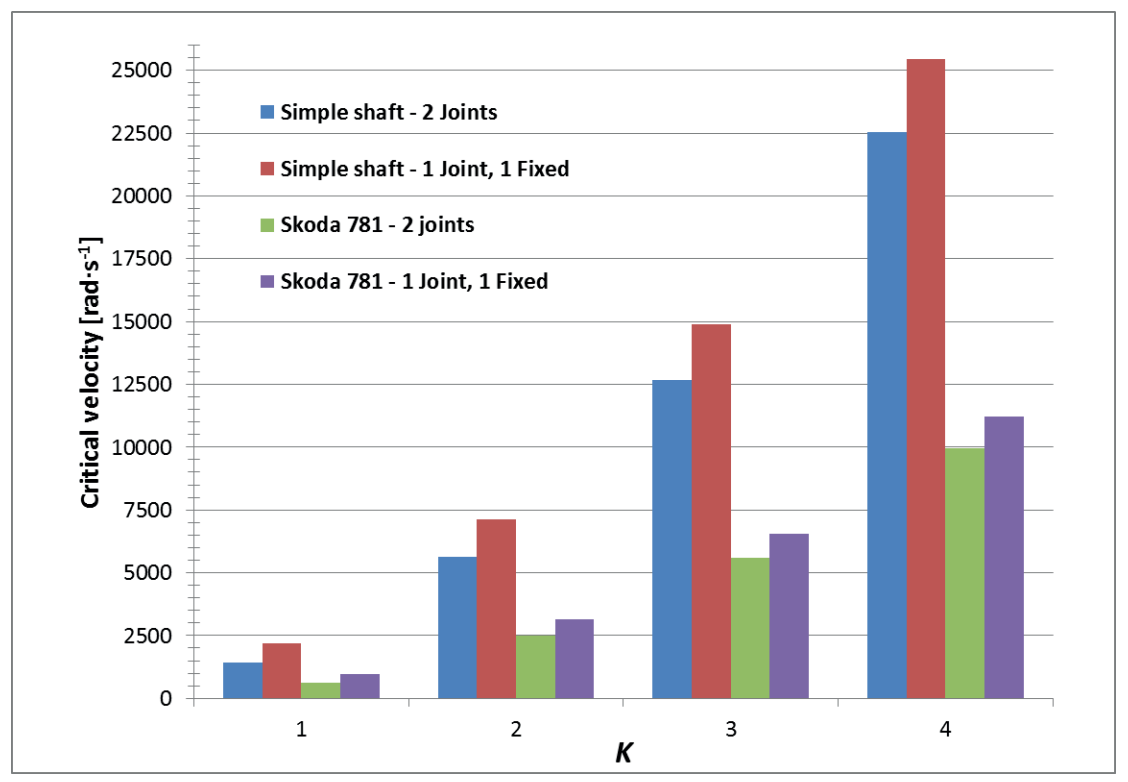

Figure 4 Critical velocities

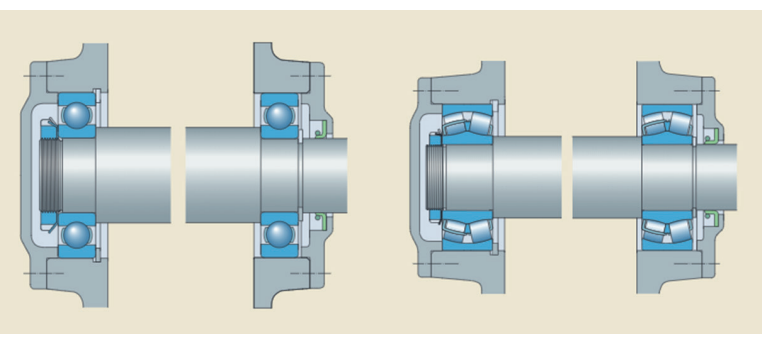

Figure 5 Shaft with joints in technical practice [7]

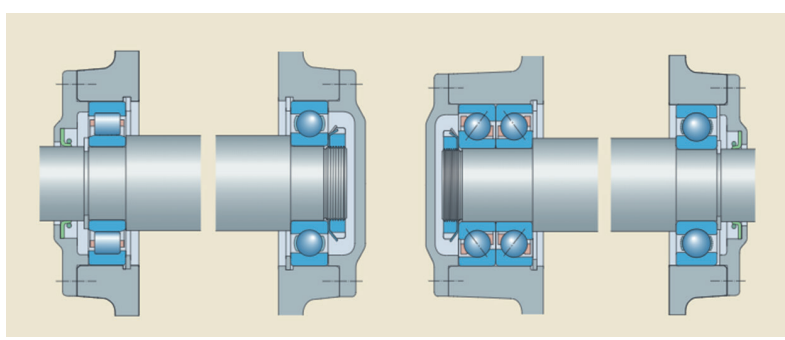

Figure 6 Shaft with joint and fixed end in technical practice [7] 


$$
Y^{I V}(x)+b Y^{\prime \prime}(x)-c Y(x)=0,
$$

where

$$
b=\frac{\rho S r^{2}}{4 E J}\left(\Omega^{2}-\omega^{2}\right), c=\left(\Omega^{2}+\omega^{2}\right) .
$$

Applying the boundary conditions for ends with joints (see Table 1) the particular solution of Equations (19) has assumed the form:

$$
Y(x)=Y_{\text {const }} \sin p_{K} x
$$

where $l$ is length of shaft, $p_{K}=\frac{K \pi}{l}$, and $K=1,2, \ldots$.

Substituting Equation (20) to Equation (18) one obtains the frequency equation

$$
\left(p_{K}^{4}-b p_{K}^{2}-c\right) Y_{\text {const }} \sin p_{K} x=0 .
$$

Calculating the above equation, the eigenvalues of frequencies of the vibration have the form:

$$
\Omega_{n}=\left(\frac{E J}{q S}\right)^{\frac{1}{2}}\left(\frac{\left(\frac{K \pi}{l}\right)^{4}-\frac{\rho S \omega^{2}}{E J}\left[1-\left(\frac{K \pi r}{2 l}\right)^{2}\right]}{1+\left(\frac{K \pi r}{2 l}\right)^{2}}\right)^{\frac{1}{2}} .
$$

\section{The testing model}

Derived equations were tested on two different examples (mounting type $\mathrm{A}$ and $\mathrm{E}$ in Table 2). The first one was simple shaft with circular cross-section and the second was shaft from the Skoda 781. Parameters of both examples are shown in Table 3.
Results of calculations are shown inn Figure 4.

Meaning of $K$ in Figure 4 and Table 4 is shown in Figure 2.

It is clear from the Equations (10) and (15) that the shaft parameters also influence the critical velocity (see Figure 4 and Table 4). The critical speed is proportional to the parameter $\sqrt{E J}$ and inversely proportional to parameters $l^{2}$ and $\sqrt{\mu}$.

There can be seen how different mounting types can change values critical velocities. The exact values are shown in Table 4.

\section{Conclusions}

In Table 2 are presented all the possibilities of mounting types of shafts and beams. The usual technical designs of the shaft's ends are presented in Figure 5 (shaft with joint) and Figure 6 (shaft with join and fixed end).

As shown in Figure 4 and Table 4, the critical velocity depends significantly on the mounting type of shaft's ends and parameters $E, J, l, \mu$ of the shaft. It is clear from results that the mounting types of shaft's ends need to be taken into account when calculating the modal and spectral properties of shafts.

\section{Acknowledgement}

The work presented in this paper was supported by grant IGS: 2019 - UTT 8210-010 of the Institute of Technology and Business in Ceske Budejovice.

\section{References}

[1] ERTURK, A. T., KARABAY, S., BAYNAL, K., KORKUT, T. Vibration noise harshness of a light truck driveshaft, analysis and improvement with six sigma approach. Acta Physica Polonica A [online]. 2017, 131(3), p. 477-481. ISSN 0587-4246, eISSN 1898-794X. Available from: https://doi.org/10.12693/APhysPolA.131.477

[2] RODRIGUEZ-CIANCA, D., RODRIGUEZ-GUERRERO, C., VERSTRATEN, T., JIMENEZ-FABIAN, R., VANDERBORGHT, B., LEFEBER, D. A Flexible shaft-driven remote and torsionally compliant actuator (RTCA) for wearable robots. Mechatronics [online]. 2019, 59, p. 178-188. Available from: https://doi.org/10.1016/j.mechatronics.2019.04.004

[3] XU, H.-B., TANG, S., XI, H.-F., GAO, P.-Y., LI, M.-Y. Joint interface during arc milling brazing of aluminium alloy to low carbon steel with cutter milling at various rotation speeds. Rare Metals. 2017, 36(11), p. 872-877. ISSN 1001-0521, eISSN $1867-7185$.

[4] ZHANG, G., DU, J., TO, S. Study of the workspace of a class of universal joints. Mechanism and Machine Theory [online]. 2014, 73, p. 244-258. ISSN 0094-114X, eISSN 1873-3999. Available from: https://doi.org/10.1016/j. mechmachtheory.2013.11.004

[5] HRUBY, P., NAHLIK, T., SMETANOVA, D. Mathematical modelling of shafts in drives. Communications-Scientific letters of the University of Zilina [online]. 2018, 20(4), p. 36-40. ISSN 1335-4205, eISSN 2585-7878. Available from: http://komunikacie.uniza.sk/index.php/communications/article/view/637

[6] ZOUL, V., KOVAC, P. A brief overview about the development of torsional vibration calculation and education of methods for their calculation. Scientific Journal of Silesian University of Technology. Series Transport [online]. 2018, 99, p. 205-211. ISSN 0209-3324. Available from: https://doi.org/10.20858/sjsutst.2018.99.19

[7] Rolling bearings - SKF group [online]. 2018. [Viewed 04-06-2019]. Available from: https://www.skf.com/binary/ 21-121486/Rolling-bearings---17000-EN.pdf 
[8] JULIS, K., BREPTA, R. Mechanics / Mechanika (in Czech). Prague: SNTL, 1987. REKTORYS, K. Variational methods in mathematics, science and engineering. Springer Science \& Business Media, 2012. ISBN 9789401164504.

[9] Group of Authors. Flexibility and strength II / Pruznost a Pevnost II (in Czech). Prague: Czech Technical University in Prague (CVUT), 1979.

[10] RALSTON, A., RABINOWITZ, P. A first course in numerical analysis. 2. ed. Dover Publications, 2001. ISBN 9780486414546.

[11] REKTORYS, K. Solving ordinary and partial boundary value problems in science and engineering. 1. ed. CRC Press, 1998. ISBN 9780849325526.

[12] REKTORYS, K. Variational methods in mathematics, science and engineering. Springer Science \& Business Media, 2012. ISBN 9789401164504.

[13] HRUBY, P. Cardan coupling shaft vibrations in the rotating plane. PhD. Thesis. Plzen: University of Mechanical and Electrical Engineering (VSSE), 1979. 